\title{
EBV-dUTPase Modulates Host Immune Responses Potentially Altering the Tumor Microenvironment in EBV-associated Malignancies
}

\author{
Maria Eugenia Ariza ${ }^{1,2}$ and Marshall V. Williams ${ }^{{ }_{1,2}}$ \\ ${ }^{1}$ Department of Cancer Biology and Genetics, The Ohio State University, USA \\ ${ }^{2}$ Institute for Behavioral Medicine Research, The Ohio State University, Wexner Medical Center, Columbus, Ohio, \\ USA
}

${ }^{*}$ Corresponding author: Marshall V. Williams, Department of Cancer Biology and Genetics, The Ohio State University, Institute for Behavioral Medicine Research, The Ohio State University, Wexner Medical Center, Columbus, Ohio, USA, Tel: (614) 293-6175; Fax: (614) 366-2097; E-mail: williams.70@osu.edu

Citation: Maria Eugenia Ariza and Marshall V. Williams (2016) EBV-dUTPase Modulates Host Immune Responses Potentially Altering the Tumor Microenvironment in EBV-associated Malignancies. Curr Res HIV/AIDS (2016): 1-9.

Received: 01September, 2016; Accepted: 08 September, 2016; Published: 13 September, 2016

\begin{abstract}
While the use of long-term antiretroviral therapy (ART) has improved immune function and reduced the incidence of some malignancies in human immunodeficiency virus (HIV-1) infected patients, this is not the case for non-Hodgkin's lymphoma, an AIDS-defining cancer, and Hodgkin lymphoma, a non-AIDS defining cancer. Epstein-Barr virus (EBV) is an independent factor that adversely affects risk and/or survival among patients with Diffuse Large B cell Lymphoma (DLBCL) or classical Hodgkin lymphoma in immunocompetent patients as well as in HIV-1 infected individuals on ART. While cells infected with EBV in EBV-associated malignancies generally express one type of the latency programs, a small number of cells in these tumors are expressing EBV genes associated with lytic replication of the virus, which suggests that products from lytic or abortive-lytic replication may contribute to lymphomagenesis. However, the potential roles of these proteins in lymphomagenesis remain unclear. In this study we demonstrate that the EBV deoxyuridine triphosphate nucleotidohydrolase (dUTPase), an early protein produced during abortive/lytic EBV replication, is expressed in nasopharyngeal carcinoma (NPC) tumors in a mouse model of NPC, an EBV associated malignancy. Furthermore, screening of sera from 4 cohorts of patients diagnosed with AIDS, DLBCL, NPC and breast cancer (BC) by ELISA revealed an increase in IgG antibodies to the EBV-dUTPase in a subset of patients with AIDS, DLBCL and NPC relative to the controls. Finally, using an in vitro model of EBV infection we demonstrate that the EBV-dUTPase also inhibits T-cell function thus, allowing the proliferation of EBV immortalized B-cells. Altogether, our data support the premise that the EBV-dUTPase can modulate host immune responses and potentially alter the tumor microenvironment by promoting the survival/proliferation of immortalized B-cells, which may lead to lymphomagenesis.
\end{abstract}

\section{Keywords:}

Epstein-Barr virus, dUTPase, lymphomagenesis

\section{Introduction}

It is estimated that approximately 35 million people worldwide and 1 million in the U.S. are infected with human 
Citation: Maria Eugenia Ariza and Marshall V. Williams (2016) EBV-dUTPase Modulates Host Immune Responses Potentially Altering the Tumor Microenvironment in EBV-associated Malignancies.Curr Res HIV/AIDS (2016): 1-9.

immunodeficiency virus (HIV) [1, 2]. While the use of long-term antiretroviral therapy (ART) has improved immune function and reduced the incidence of some malignancies in HIV-infected patients, this is not the case for non-Hodgkin's lymphoma (NHL), an AIDS-defining cancer, or Hodgkin lymphoma (HL), a non-AIDS defining cancer [3-11]. Epstein-Barr virus (EBV) is an oncogenic herpesvirus,which infects a significant percentage ( $>95 \%$ ) of the population worldwide. EBV establishes latency in B-cells following primary infection, where one of four latency gene expression programs may function but no new virus is produced. However, reactivation of the latent virus may occur multiple times during a person's lifetime resulting in abortive lytic /lytic replication which is necessary for transmission and maintenance of a persistent infection.

EBV has been demonstrated to be an independent factor that adversely affects risk and/or survival among patients with Diffuse Large B cell Lymphoma (DLBCL) or classical Hodgkin lymphoma (cHL) in immunocompetent patients [12-18] as well as in HIV-infected patients on ART $[3,5,6,9,19]$. Studies to examine immune responses to EBV as well as the role of EBV encoded proteins in cellular transformation have focused primarily on those proteins and RNAs expressed during the various forms of latency. These studies have demonstrated unequivocally the role of latent membrane proteins (LMP) -1 and $-2 \mathrm{~A}$ in the transformation process and the immunological response of the host to these proteins $[20,21]$. Numerous studies have demonstrated the importance of the tumor microenvironment in contributing to tumor growth and progression. Within this environment stromal cells, immune cells and vascular cells "cross-talk" with tumor cells. While cells infected with EBV in EBV-associated "tumors" are generally expressing one type of the latency programs, a small number of cells in these tumors are expressing EBV genes associated with lytic replication of the virus [22-29], suggesting that products from lytic or abortive-lytic replication of EBV may contribute to tumor growth/survival. Data from in vitro studies as well as studies using SCID and humanized mouse models support this premise [30-33]. Thus, virus encoded proteins expressed under these conditions could be regarded as potential targets for treatment. However, the potential role of these lytic replication-associated proteins in immune evasion in immunocompetent or immunosuppressed individuals as well as in promoting tumor growth/survival of malignant cells is unknown.

We have identified a new class of pathogen-associated molecular pattern (PAMP) proteins, deoxyuridine triphosphate nucleotidohydrolases; (dUTPases) that have novel immunoregulatory functions that may contribute to the pathophysiology of diseases caused by these viruses [34-40]. Using the EBV-dUTPase as the prototype, our studies have demonstrated conclusively that the EBV-dUTPase possesses, independent of its enzymatic activity, novel functions acting as a PAMP for toll-like receptor (TLR) 2 leading to the activation of NF-kB and subsequent modulation of downstream genes involved in oncogenesis, chronic inflammation, effector T-cell function and neurotransmitter function [35-40]. These studies have shown that the EBV-dUTPase is secreted from B-cells (plasma cells) in exosomes during abortive-lytic replication of EBV[39] and that the EBV-dUTPase protein induced a significant increase in the secretion of the pro-inflammatory $\mathrm{T}_{\mathrm{H}} 1 / \mathrm{T}_{\mathrm{H}} 17$ cytokines IL- $1 \beta$, IL-6, IL-8, IL-12p70, TNF- $\alpha$ and IFN- $\gamma$ as well as the anti-inflammatory cytokine IL-10 in human dendritic cells and PBMCs [2-4,6]. These results suggest that the EBV-dUTPase may be acting as an intercellular signaling molecule capable of modulating the cellular microenvironment.In the present study we demonstrate that: (i) the BLLF3 gene, which encodes for the dUTPase, is expressed in an in vivo model of nasopharyngeal carcinoma (NPC), (ii) EBV-dUTPase specific antibodies are elevated in AIDS patients as well as patients with DLBCL or NPC, and(iii) the EBV-dUTPase up-regulates the expression of microRNA-155, which is associated with aberrant inflammatory responses as well as oncogenesis. Furthermore, using an in vitro model, we demonstrate that the EBV-dUTPase impairs the functional activity of EBV-specific T-cells to eliminate EBV infected B-cells. These results suggest that the EBV-dUTPasemay play a novel role in the establishment of a microenvironment that could contribute to the pathophysiology of EBV-associated diseases, including lymphomagenesis.

\section{Material and Methods}

Reagents. The NF- $\kappa \mathrm{B}$ luciferase promoter construct $\mathrm{pNF}-\kappa \mathrm{B}-$ Luc and the transfection control reporter vector $\mathrm{pRL}-\mathrm{TK}$, were purchased from Clontech Laboratories, Inc., (Mountain View, CA), and Promega (Madison, WI), respectively. pGL3BIC/miR155 promoter construct was a generous gift from Dr. E. Flemington (Tulane University, New Orleans, LA). pCMV-cFosand pCMV-cJun expression constructs were a gift from Dr. Phillip Buckhaults (University of South Carolina, Columbia, SC).

\section{Purification of the EBV-dUTPase}

Detailed methods for the purification of the EBV-dUTPase have been previously reported $[35,40]$. All EBV-dUTPase preparations were tested as described previously [35] and were free of detectable levels of LPS, peptidoglycan (SLP-HS), DNA or RNA. Protein concentration was determined with a Coomassie Brilliant Blue dye-binding assay (Bio-Rad Laboratories, Hercules, CA) using bovine serum albumin as the standard. The purified EBV-dUTPase used in these studies was stored at $-80^{\circ} \mathrm{C}$ at stock concentrations of $0.2 \mathrm{mg} / \mathrm{ml}$ and $0.5 \mathrm{mg} / \mathrm{ml}$.

\section{EBV-dUTPase Neutralization Assays}

EBV-dUTPase assays were performed as described previously [38]. Briefly, $5 \mu \mathrm{l}$ of human serum was mixed with $5 \mu \mathrm{l}$ of purified-dUTPase (3-5 units of enzyme) for $30 \mathrm{~min}$ at room temperature prior to assaying for enzymatic 
Citation: Maria Eugenia Ariza and Marshall V. Williams (2016) EBV-dUTPase Modulates Host Immune Responses Potentially Altering the Tumor Microenvironment in EBV-associated Malignancies.Curr Res HIV/AIDS (2016): 1-9.

activity as described previously [38]. For positive controls, assays were performed in the presence of human serum lacking anti-EBV-dUTPase antibodies; while negative controls lacked EBV-dUTPase. A unit of EBV-dUTPase activity was defined as the amount of enzyme required to convert 1 nmole of dUTP to dUMP and pyrophosphate $/ \mathrm{min} / \mathrm{ml}$ of enzyme at $37^{\circ} \mathrm{C}$. Serum with neutralizing units greater than or equal to two standard deviations from the control were considered positive for neutralization.

\section{NPC Mouse Model}

C666-1, an EBV genome positive NPC cell line [41], was grown and maintained in RPMI 1640 supplemented with 10\% fetal bovine serum, penicillin $(100 \mathrm{U} / \mathrm{ml})$ and streptomycin $(100 \mu \mathrm{g} / \mathrm{ml}$ ). SCID mice (males 6-8 weeks old, Jackson Laboratories) were injected subcutaneously with C666-1 cells $\left(2 \times 10^{6}\right)$ and sacrificed 25 days post-inoculation. Tumors were isolated, RNA extracted and examined for the expression of BALF5 (DNA polymerase), EBNA1 (Epstein-Barr nuclear antigen 1), LMP1 (Latent membrane protein-1), BZLF1 (Zebra protein) and BLLF3 (dUTPase). All procedures were performed in accordance with NIH Guidelines for the Care and Use of Laboratory Animals and approved by The Ohio State University Institutional Laboratory Animal Care and Use Committee.

\section{RNA Extraction and Quantitative Real-time PCR}

Total RNA from SCID mice tumors was extracted using TRIzol reagent (Invitrogen) according to the manufacturer's protocol. First-strand cDNA synthesis was performed using random primers and MultiScribe reverse transcriptase (Applied Biosystems). A cDNA sample (50-ng) was examined by qRT-PCR for BLLF3, BZLF1, BALF5, EBNA1 and LMP1 levels using ABI custom TaqMan gene expression assays [42, 43]. The sequences of primers and TaqMan probes used are as follow. BLLF3 - Forward primer (F): 5'-GGACGTCAGCCTGACCAACT-3', Reverse primer (R): CAGAAGCGCCGGTACTTGTT-3', Probe: 5'-(6FAM)-CCAGACCGTGTTCCT-(TAMRA)-3'.BZLF1-

5'AATTTAAGAGATCCTCGTGTAAAACATCT-3',

BZLF1-R: 5'-GCGCCTCCTGTTGAAGCA-3',

5'-(6FAM)-AATGGAGTCAACATCCAG-(TAM-

RA)-3'. BALF5-F: 5'-CGGAAGCCCTCTGGACTTC-3', BALF5-R: 5'-CCCTGTTTATCCGATGGAATG-3', Probe: 5'-(6FAM)-TGTACACGCACGAGAATGCGCC-(TAM-

RA)-3'. EBNA1-F: 5'-TACAGGACCTGGAAATGGCC-3', EBNA1-R: 5'-TCTTTGAGGTCCACTGCCG-3', Probe: 5'-(6FAM)-AGGGAGACACATCTGGACCAGAAGGC-(TAMRA)-3'. LMP1-F: 5'-CAGTCAGGCAAGCCTATGA-3', LMP1-R: 5'-CTGGTTCCGGTGGAGATGA-3', Probe: 5'-(6FAM)-GTCATAGTAGCTTAGCTGAAC-(TAMRA)-3'.

Samples were normalized to the endogenous control GAPDH and expressed as the mRNA expression levels relative to untreated control using the $\Delta \Delta \mathrm{C} \tau$ method. All reactions were performed in triplicate on an ABI 7900HT System.

\section{Cell culture}

Human embryonic kidney 293 (HEK293) cells stably expressing human TLR2 were purchased from Invivogen (San Diego, CA). Cells were maintained in DMEM supplemented with L-glutamine $(2 \mathrm{mM})$, HEPES $(10 \mathrm{mM})$, sodium pyruvate (1\%), and 10\% FBS, plus blasticidin (HEK293-TLR2).

Human peripheral blood mononuclear cells (PBMCs) from healthy subjects were obtained from Astarte Biologics (Cat\#1001 Lot \# 1704OC12).

U1 cells, a subclone of the HIV-1-infected monoblastoid cell line U937, were maintained in RPMI 1640 medium supplemented with $100 \%$ fetal calf serum, penicillin $(250 \mathrm{U} / \mathrm{ml})$ and streptomycin $(250 \mathrm{~g} / \mu \mathrm{ml}) . \mathrm{ACH}-2$ cell line is a HIV-1-infected CEM T cell clone (A3.01) with one integrated proviral copy. ACH-2 cells were maintained in RPMI 1640 supplemented with $10 \mathrm{mM}$ HEPES, $2 \mathrm{mM}$ L-glutamine, 90\%; heat inactivated fetal bovine serum, $10 \%$. U1 and ACH- 2 cell lines were obtained from the NIH AIDS Research and Reagent Program, Division of AIDS, NIAID.

\section{Luciferase Reporter Gene Assays}

TLR2-HEK293 expressing cells $\left(2.5 \times 10^{5}\right)$ were seeded into 12 -well plates and transiently transfected $24 \mathrm{~h}$ later using lipofectamine transfection reagent (Invitrogen; Carlsbad, CA), as we have previously described [37, 40]. Briefly, cells were transfected with $\mathrm{pBIC/miR} 155$ promoter-Luc, pRL-TK reporters and co-transfected with $0.5 \mu \mathrm{g}$ of Fos and Jun, p65NFkB expression vectors, a combination thereof or empty vector. After 24-36 h following transfection, cells were treated with purified EBV-dUTPase $(10 \mu \mathrm{g} / \mathrm{ml})$ for $8 \mathrm{~h}$ or left untreated. Cell lysates were prepared and reporter gene activities were measured using the dual-luciferase reporter system (Promega, Madison, WI). Data was normalized for transfection efficiency and reporter activity expressed as the mean relative stimulation \pm SD.

EBV Specific T-Cell Assay. EBV specific T-cell assays were performed as described previously [44]. Briefly, PBMCs were obtained from five healthy human donors through an Ohio State University-approved IRB protocol. PBMCs were isolated by density gradient centrifugation using Histopaque-1077 (Sigma) by standard procedures and cultured in RPMI 1640 medium containing $20 \%$ fetal bovine serum. Cells were cultured at a density of $7 \times 10^{5}$ cells $/ \mathrm{ml}$ using 24-well tissue culture plates and infected with $10^{6}$ transforming units of the B95-8 strain of EBV. For those studies in which the EBV-dUTPase protein was employed, it was added simultaneously with the virus at various concentrations $(0,0.1$, 1 or $10 \mu \mathrm{g} / \mathrm{ml}$ ) and replenished every 3 days for a period of two weeks. Half of the medium was exchanged every three days. After 28 days, cells were harvestedand cell number determined.

\section{HIV-1 Induction Assay}

$\mathrm{U} 1$ and ACH- 2 cells $\left(2 \times 10^{6}\right.$ cells/well) were seeded in 6-well tissue culture plates and treated with various concentrations 
Citation: Maria Eugenia Ariza and Marshall V. Williams (2016) EBV-dUTPase Modulates Host Immune Responses Potentially Altering the Tumor Microenvironment in EBV-associated Malignancies.Curr Res HIV/AIDS (2016): 1-9.

$(0-10 \mu \mathrm{g} / \mathrm{ml})$ of EBV-dUTPase recombinant protein for $48 \mathrm{~h}$. Following treatment, cells were collected, lysed and protein extracts from untreated or EBV-dUTPase treated cells were analyzed for HIV-1 p24 and HIV-1 gp41 levels by western blot.

\section{Western Blot Analysis}

Whole cell lysates from untreated or EBV-dUTPase treated $\mathrm{U} 1$ and $\mathrm{ACH}-2$ cells were prepared in $100 \mu$ lof RIPA buffer, containing $2 \mathrm{mM}$ PMSF and a protease inhibitor cocktail (Sigma Chemical Co. St. Louis MO), and protein concentration determined as described above. Protein extracts $(25 \mu \mathrm{g})$ were size-fractionated in $12 \%$ polyacrylamide gels under standard SDS-PAGE conditions ( $160 \mathrm{~V}$ for $1 \mathrm{~h}$ ), and then transferred onto PVDF membranes (Bio-Rad Laboratories, Hercules, CA) using a Transblot apparatus (Bio-Rad) for 20' at $15 \mathrm{~V}$. Following protein transfer, membranes were blocked with 5\% dry-milk in TBS-T for $1 \mathrm{~h}$ and analyzed for HIV-1 p24 and HIV-1 gp41 protein levels by immunoblotting using AIDS patient sera overnight at $4^{\circ} \mathrm{C}$ followed by incubation with anti-human-IgG horseradish peroxidase (HRP)-conjugated secondary antibody (Sigma Chemical Co. St. Louis MO) at 1:10000 dilution in blocking buffer ( $1 \mathrm{~h}$ at room temperature). Finally, the protein bands were visualized using the enhanced chemiluminescence detection system (ECL Western blotting detection reagents, GE Healthcare).

\section{Results}

BLLF3 is expressed in EBV-associated NPC tumors and anti-EBV-dUTPase antibodies are pres-
ent in sera of NPC patients.

To determine whether EBV-dUTPaseis expressed in EBV associated tumors a transplantable mouse tumor model was employed. SCID mice were injected subcutaneously with C666-1 cells, an EBV genome positive cell line that causes NPC-like tumors in SCID mice. Twenty five days post-inoculation, mice were sacrificed, tumors isolated and the RNA extracted and examined for the expression of several EBV encoded genes, including BLLF3, which encodes for the dUTPase, by qRT-PCR. As shown in Figure 1, with the exception of a tumor from animal \#4, all other tumors examined expressed BZLF1 (encoding the immediate early transcriptional activator), BALF5 (DNA polymerase) and BLLF3 (dUTPase). These results demonstrate that reactivation of latent virus has occurred in these tumors and that BLLF3 is being expressed. Tumor \#4 did not express any EBV genes (lytic or latent) and thus, may represent a situation in which the tumor cells lost the viral genome, which is known to occur repeatedly in EBV-genome positive epithelial tumor cells.

We then asked whether a humoral response directed against EBV-dUTPase could be detected in the sera of patients with EBV-related malignancies. The presence of EBV-dUTPases pecific antibodies were elevated in patients with AIDS (45\%, 22 cases), DLBCL (36\%, 36 cases) and nasopharyngeal carcinoma

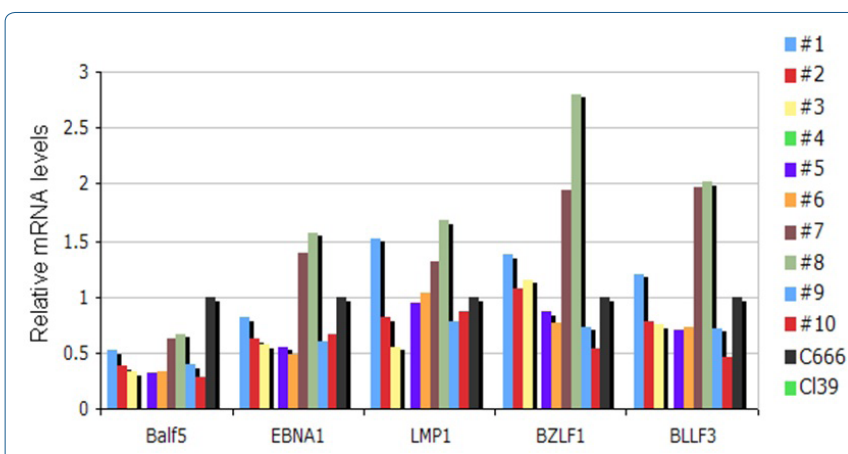

Figure 1: EBV-dUTPase is expressed in a mouse model of NPC. SCID mice were injected s.c with $\mathrm{C} 666-1$ cells $\left(2 \times 10^{6}\right)$. At 25 days post-inoculation, mice were sacrificed, tumors isolated and mRNA expression levels for the EBV genes BLLF3, BZLF1, BALF5, EBNA1 and LMP1 were examined by qRTPCR and normalized to the endogenous control GAPDH. Data represent the mean relative mRNA expression in 10 tumors. All reactions were performed in triplicate.

(NPC) $(44 \%, 16$ cases)when compared to patients with breast cancer $(2.9 \%, 68$ cases) and healthy controls (4.6\%, 160 cases). Interestingly, of the EBV-dUTPase positive AIDS patients, all but one were on ART. Furthermore, of the 13 DLBCL patients who were positive for anti-EBV-dUTPase antibodies only three patients exhibited positive reactivity to a peptide-based ELISA containing immunodominant epitopes of EBNA1 (BKRF1) and viral capsid antigen (VCA)-p18 (BFRF3) [45], suggesting the possibility that abortive lytic replication may be occurring in a large percentage of the DLBCL patient cohort.

\section{EBV-dUTPase induction of BIC/miR155 promot-} er activity requires AP-1 and NF- $\mathrm{B}$ sites.

Previous microarray data analysis by our group [39] revealed that EBV-dUTPase induces the expression of the B-cell Integration Cluster (BIC) transcript, the precursor of miR-155, by 12 -fold. To determine the possible contribution of AP-1 and NF- $\kappa \mathrm{B}$ response elements in mediating the activation of BIC by EBV-dUTPase, luciferase reporter assays using the BIC/miR155 promoter were performed in TLR2-HEK293 expressing cells. Briefly, cells were transiently transfected with $\mathrm{pBIC/miR155}$ promoter-Luc, pRL-TK reporter vectors and co-transfected with c-Fos + c-Jun, p65NF- $\kappa \mathrm{B}$ expression constructs alone, a combination thereof or empty vector. After 24-36 h, cells were stimulated with EBV-dUTPase for $8 \mathrm{~h}$ or left untreated and analyzed for luciferase reporter activity, as we have described [37, 40]. The data presented in Figure 2 indicate that transcriptional activation of the BIC/miR155 promoter following EBV-dUTPase treatment of TLR2-HEK293 expressing cells requires AP-1 and NF- $\kappa \mathrm{B}$ sites. These results suggest that c-Fos, $\mathrm{c}-J u n$ and p65NF- $\kappa B$ transcription factors may play a role in EBV-dUTPase mediated induction of BIC promoter transcription.

\section{EBV-dUTPase promotes the proliferation/survival}

\section{of B-cells latently infected with EBV}

It is well known that cytotoxic T-lymphocytes (CTLs, CD8 ${ }^{+}$) are responsible for limiting the proliferation and for clearing 


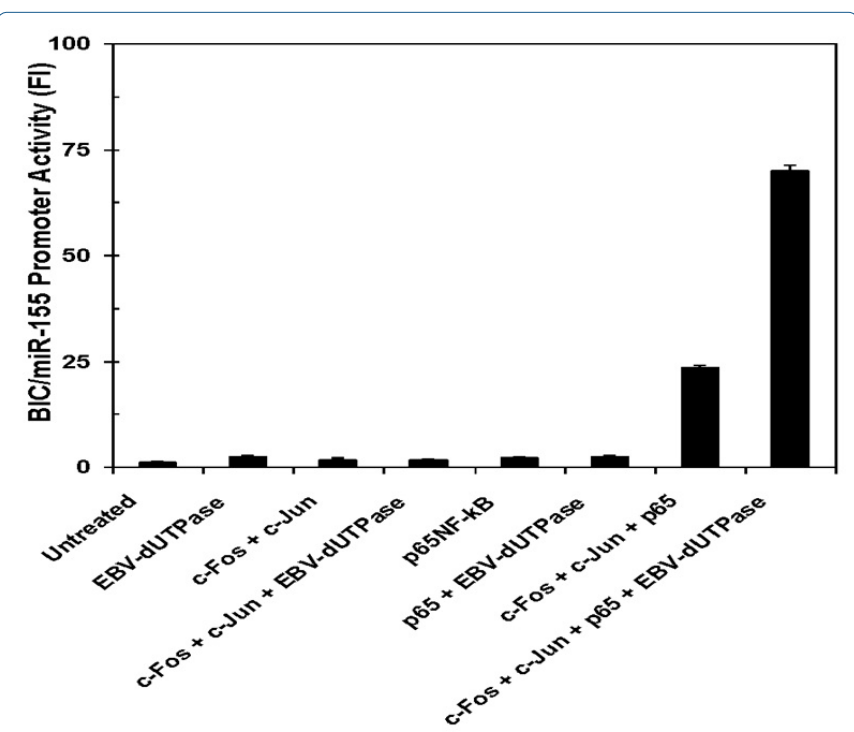

Figure 2: EBV-dUTPase induction of $\mathrm{BIC} / \mathrm{miR} 155$ promoter activity requires c-Fos, c-Jun and p65NF-KB transcription factors. TLR2-HEK293 cells were transiently transfected with $\mathrm{pBIC/miR} 155$ promoter-Luc, $\mathrm{pRL}-\mathrm{TK}$ reporter vectors and co-transfected with c-Fos + c-Jun, p65NF-KB expression constructs, a combination thereof or empty vector. After 24-36 h, cells were stimulated with EBV-dUTPase $(10 \mu \mathrm{g} / \mathrm{ml})$ for $8 \mathrm{~h}$ or left untreated and analyzed for luciferase reporter activity, as we have described [12].

cells latently infected with EBV [20]. However, our knowledge concerning whether viral encoded proteins that are expressed during lytic or abortive infection may modulate T-cell responses to cells productively or latently infected with EBV is rather limited [46].

We have demonstrated thatEBV-dUTPase inhibits T-cell proliferation in vitro following anti-CD3 stimulation [35]. Microarray analyses of human dendritic cells demonstrated that the EBV-dUTPase modulated pathways (PD-1: PD-L1/ L2; ICOS:ICOSL; IL-15/IL-15R; IL-4I1; Egr-1 and PAG1) that could promote T-cell tolerance/exhaustion [39]. To evaluate the potential effect of EBV-dUTPase-mediated inhibition of T-cell proliferation on EBV-specific T-cell responses, an in vitro model was used. Briefly, PBMCs were infected with the B95-8 transforming strain of EBV in the presence and absence of EBV-dUTPase protein. While transformation of resident B-cells normally occurs, the proliferation and expansion of this $\mathrm{B}$-cell population is affected by the presence of EBV-specific CTLs [42]. Strikingly, Figure 3 shows that B-cell proliferation/ expansion was enhanced by 6 -and 10 -fold $(p<0.001)$ in cells treated with 0.1 and $10 \mu \mathrm{g} / \mathrm{ml}$ EBV-dUTPase, respectively, relative to untreated cells infected with EBV. Furthermore, treatment of Ramos B cells with EBV-dUTPase at various concentrations $(0-10 \mu \mathrm{g} / \mathrm{ml})$ did not have any effect on proliferation of B-cells (Data not shown). These data suggest that the EBV-dUTPase may be preventing the killing of B-cells latently infected with EBV by affecting the function of EBV-specific CTLs.

\section{EBV-dUTPase induces the expression of p24 and}

\section{gp41 in latent HIV-1 infected cells}

It has recently been reported that cooperation between $\mathrm{HIV}$ and EBV in infected individuals may be important in

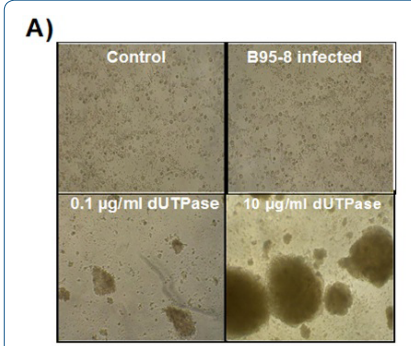

B)

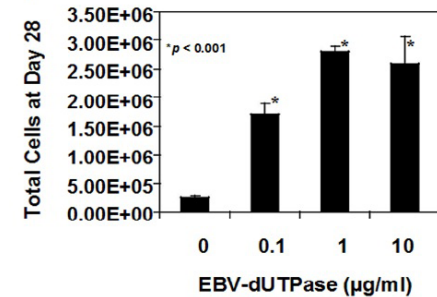

Figure 3: EBV-dUTPase enhances proliferation/survival of B-cells latently infected with EBV. A) PBMCs $\left(7 \times 10^{5}\right)$ were infected with 106 transforming units of the B95-8 transforming strain of EBV. EBV-dUTPase was added simultaneously with virus at the concentrations indicated and replenished every 3 days for two weeks. After 28 days, wells were examined for transformed B-cells. The average number of cells \pm SD over four wells was determined for each treatment: (i) Untreated control; (ii) PBMCs infected with EBV-B95; (iii) PBMCs infected with EBV and treated with EBV-dUTPase $(0.1 \mu \mathrm{g} / \mathrm{ml})$, (iV) PBMCs infected with EBV and treated with EBV-dUTPase $(10 \mu \mathrm{g} / \mathrm{ml})$. B) Histogram demonstrating increase in cell number following dUTPase treatment of EBV infected PBMCs.

promoting lymphomagenesis. To determine if the EBV-dUTPase might be a potential inducer/transactivator of HIV-1 genes, we examined the effect of the dUTPase protein in latent HIV-1 infected U1 and ACH-2 cell lines. As shown in Figure 4 , treatment of cells with various concentrations of EBV-dUTPase resulted in a dose-dependent increase in the expression of HIV-1 p24 and HIV-1 gp41 genes in U1 cells, and to a lesser degree in ACH-2 cells (data not shown), compared to base-line levels present in unstimulated cells. This study demonstrates/ supports a role for the EBV-dUTPase as a potential inducer of HIV-1 activation.

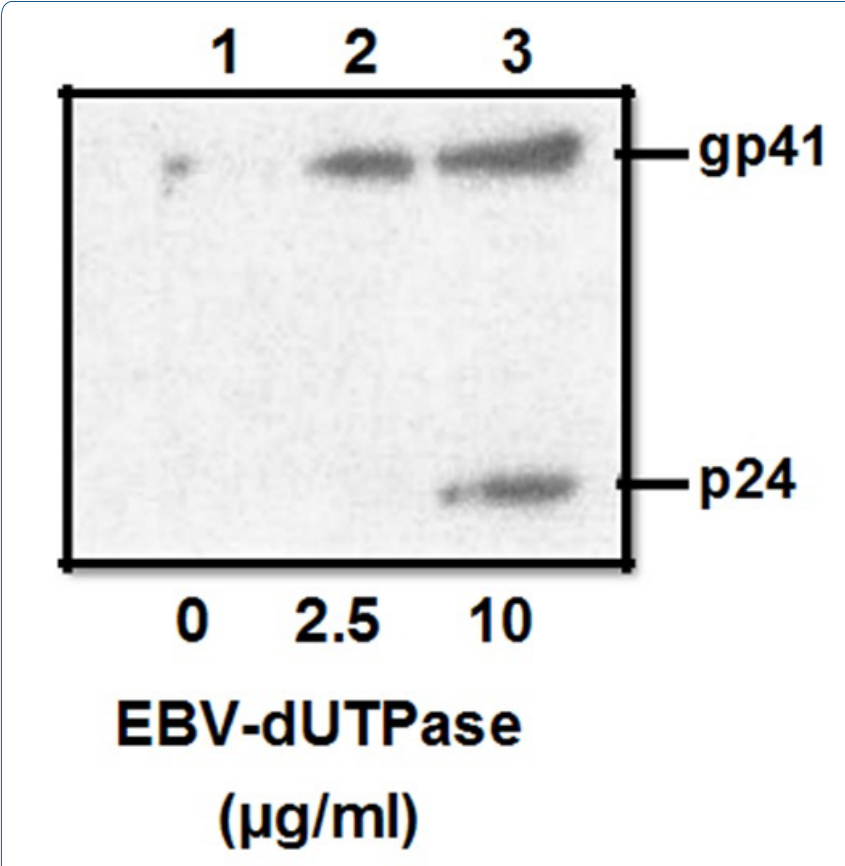

Figure 4: Induction of HIV-1 genes by EBV-dUTPase. Lysates of latent HIV-infected $A C H 2$ cells $(A)$ and $U 1$ cells $(B)$ either left unstimulated or treated with EBV-dUTPase $(2.5 \mu \mathrm{g} / \mathrm{ml}$ and $10 \mu \mathrm{g} / \mathrm{ml})$ for $48 \mathrm{~h}$ were analyzed for the expression of HIV-1 p24 and HIV-1 gp41 proteins by western blot using AIDS patient sera. Lanes 1 and 4: unstimulated; Lanes 2 and 5: treated with $2.5 \mu \mathrm{g} /$ $\mathrm{ml} \mathrm{EBV-dUTPase}$ and Lanes 3 and 6: treated with $10 \mu \mathrm{g} / \mathrm{ml}$ EBV-dUTPase. Positions of HIV-1 proteins are indicated on the right. 
Citation: Maria Eugenia Ariza and Marshall V. Williams (2016) EBV-dUTPase Modulates Host Immune Responses Potentially Altering the Tumor Microenvironment in EBV-associated Malignancies.Curr Res HIV/AIDS (2016): 1-9.

\section{Discussion}

While it is well established that there is a low level of lytic/abortive lytic replication of EBV in EBV genome positive tumor cells, studies to address the expression of EBV early proteins in these tumors as well as the potential role that these early proteins may have in oncogenic processes is unclear. Recently, Traylen et al [47] using an enrichment-proteomic approach identified several lytic cycle gene products including the EBV-dUTPase that are expressed in Burkitt's lymphoma cells. In the present study we used an in vivo model of NPC and demonstrate that the EBV-dUTPase is expressed in these tumors. Evidence for a humoral response to the EBV-dUTPaseh as been shown by Summer et al [48], in some patients with infectious mononucleosis, reactivated and chronic EBV infections as well as in some patients co-infected with HIV-1 and in this study in some patients with AIDS, DLBCL and NPC further supporting the premise that the BLLF3 gene is expressed during certain disease conditions.

The data presented in this study demonstrate that the EBV- dUTPase inhibits the functional ability of EBV-specific $\mathrm{CD}^{+}{ }^{+}$-cells to prevent the proliferation of B-cells latently infected with EBV. This observation is not due to a direct effect of the EBV- dUTPase on B-cells since B-cells express little, if any, TLR2 [49]. While the mechanism(s) by which the EBV-dUTPase inhibits $\mathrm{CD} 8^{+}$T-cell function is not known, the results of this study suggest that it may be due to a shift in the T-cell populations to a regulatory T-cell phenotype coupled with inhibition of T-cell function as well as increased B-cell proliferation. Previous studies on EBV have shown that regulatory T-cells (Tregs) are important in decreasing the EBV-specific $\mathrm{CD}^{+}{ }^{+} \mathrm{T}$-cell response to B-cells obtained from various EBV-positive malignancies, as well as B-cells from patients with infectious mononucleosis [50,51]. Interestingly, TLR2, a T-cell co-stimulatory molecule [52] has been reported to control the expansion and function of Tregs[53]. This finding opens up the possibility that the EBV-dUTPase may be inducing an immunosuppressive microenvironment by engaging TLR2 on Tregs.

Our data also demonstrate that the EBV-dUTPase increases the expression of the BIC/miR-155 (12-fold) transcript, which requires AP-1 and NF-kB. miR-155, which down-regulates BCL6 expression, acts to increase B-cell functioning and has been reported to enhance transcription and contribute to the pathogenesis of DLBCL [54]. In addition, BIC/miR-155 also contributes to the development of regulatory T-cells (Tregs) $[55,56]$. Interestingly, Baumforth et al [57] reported that EBNA-1 increased the expression of CCL20 in EBV infected Hodgkin lymphoma cell lines and that the increased levels of CCL20 correlated with increased migration of Tregs, suggesting that induction of CCL20 dampens the immune response against EBV infected cells in the tumor population. Likewise, we have demonstrated that the EBV-dUTPase induces the increased expression of CCL20 (335-fold) [39], suggesting that the EBV-dUTPase may contribute to altering the tumor microenvironment by increasing the proliferation/migration of Tregs.

We have previously demonstrated that the EBV-dUTPase inhibited T-cell proliferation [33] and that the EBV-dUTPase activates specific pathways (PD-1: PD-L1/L2; ICOS:ICOSL; IL-15/IL-15R; IL-4I1; Egr-1 and PAG1) that modulate T-cell proliferation/function [39]. IL4I1 in mature DCs encodes for a secreted L-phenylalanine oxidase that down-regulates the expression of T-cell receptor (TCR) $\partial$ chain, which inhibits T-cell proliferation $[58,59]$. Likewise, Egr-1 is a transcription factor that regulates IL-2 expression and thus its down regulation would limit $\mathrm{CD}^{+} \mathrm{T}$-cell proliferation. The down-regulation of PAG1, which is reported to establish an activation threshold for the initiation of TCR signaling, may result in T-cell unresponsiveness in conditions in which there is strong TCR in the absence of proper co-stimulation [60]. Conversely, the increased expression of ICOSL (inducible T-cell stimulator)-ICOS pathway augments $\mathrm{T}$ cell effector function, which enhances $\mathrm{T}_{\mathrm{H}} 1$ and $\mathrm{T}_{\mathrm{H}} 2$ cytokine production and stimulates IL-10 production. This may contribute to regulation of Treg cell function, $\mathrm{T}$ cell tolerance and autoimmunity [61]. Finally, the EBV-dUTPase may be altering function/activation of $\mathrm{CD}^{+} \mathrm{T}$-cells by up-regulating the inhibitory members of the B7 family PD-L2/PD-L1 (3.41 -fold), which are known to play important roles in T-cell tolerance/exhaustion in chronic virus infections $[62,63]$.

There is evidence supporting that there is cooperation between HIV and EBV in infected individuals and that it isimportant in promoting lymphomagenesis [64, 65]. However, the indirect effects of viral cooperation are difficult to examine, and in the case of EBV-associated lymphomas additional studies are needed. Using various promoter constructs, the latently expressed Epstein Barr Nuclear Antigen (EBNA) 2 and latent membrane protein (LMP)-1 have been reported to transactivate HIV-1 long terminal repeat (LTR) $[66,67]$, while the DNA polymerase, an early protein expressed during abortive -lytic and lytic replication has also been reported to transactivate HIV-1 LTR [68]. In this study, we demonstrate that the EBV-dUTPase also induces the expression of HIV-1 p24 and gp41 genes. HIV gene products may also modulate EBV functions. The HIV-1tat protein has been reported to modulate cell proliferation and apoptosis of EBV-immortalized cell lines [69]. Likewise,Iyenger and Schwartz [70] reported that the gp120 from X4 strains of HIV-1 enhanced B cell lymphomagenesis when B cells were exposed to EBV. gp120 has also been reported to be important in immune activation in female genital epithelium [71] and in HIV replication [72] through TLR2 activation. Interestingly, Abergel et al [73] reported the presence of a "hidden dUTPase" in the gp120 sequence and they suggested that an ancestral dUTPase gene evolved into the present primate lentivirus CD4 and chemokine receptor interacting region of gp 120 . 
Citation: Maria Eugenia Ariza and Marshall V. Williams (2016) EBV-dUTPase Modulates Host Immune Responses Potentially Altering the Tumor Microenvironment in EBV-associated Malignancies.Curr Res HIV/AIDS (2016): 1-9.

Altogether the data presented in this study and our previous studies suggest that the EBV-dUTPase canalter the tumor microenvironment, based upon its novel functions as a PAMP, and immunopotentiate the pathophysiological effects towards tumor development. As shown in Figure 5, we propose that the infiltration of plasmablasts/plasma cells within the tumor microenvironment [74-79] results in the increased release of EBV-dUTPase from these cells due to lytic/ abortive-lytic replication of EBV [80-82]. Ligation of the EBV-dUTPase with TLR2 on CD14 ${ }^{+}$antigen presenting cells (APCs) and T-cells results in the activation of specific pathways (IL-6 and BIC/miR-155) that promote the proliferation/functioning of EBV-genome positive B-cells and simultaneously promote pathways (PD-1:PD-L1/L2; ICOS:ICOSL; IL-15/ IL-15R; IL-4I1; Egr-1 and PAG1) that modulate T-cell proliferation/function leading to T-cell tolerance/exhaustion.The outcome of these interactions between APCs and T-cells, via ligation/engagement of these pathways, in an environment in which effector T-cell proliferation and function are diminished coupled with an increased formation of a suppressive regulatory T-cell (Treg) population.

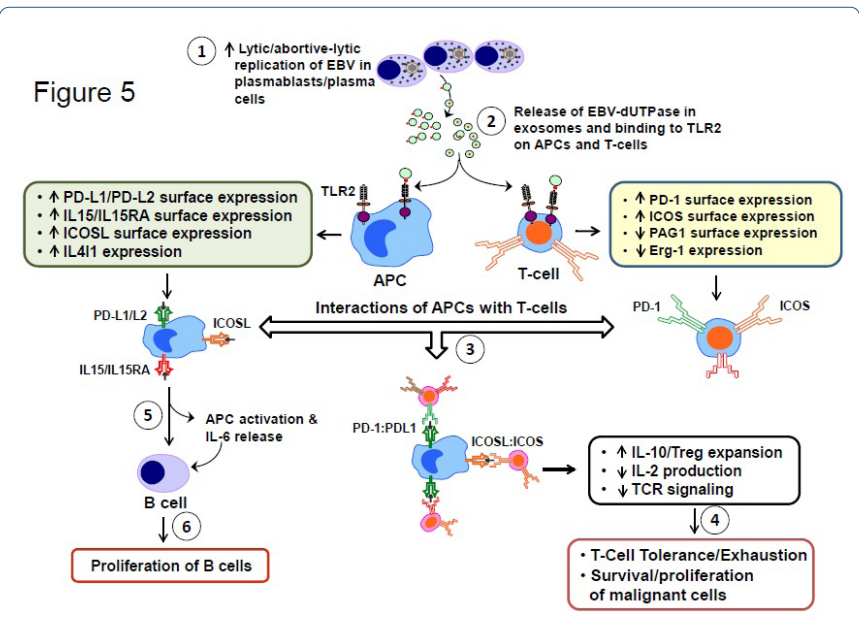

Figure 5: Schematic diagram depicting the novel functions of EBV-dUTPase and potential implications in human diseases.1. Abortive/lytic replication of $\mathrm{EBV}$ in plasmablasts/plasma cells results in the expression of EBV-dUTPase and its subsequent release either through pyroptosis (localized effect) or in exosomes (systemic effect). 2. The EBV-dUTPase then modulates the cellular microenvironment by engaging TLR2 on target cells (CD14 ${ }^{+}$antigen presenting cells (APC) as well as T-cells) resulting in the activation of specific pathways (PD-1:PD-L1/L2; ICOS:ICOSL; IL-15/ IL-15R; IL-4I1; Egr-1 and PAG1) that modulate immune responses to EBV leading to T-cell tolerance/exhaustion, which contributes to a cellular environment supporting the survival and proliferation of malignant cells. $(3,4) \cdot 5$. Activation of TLR2 on APC also results in NF-KB activation and subsequent induction/secretion of IL-6. 6. IL-6 acts as a growth factor for $\mathrm{B}$ cells leading to $\mathrm{B}$ cell proliferation.

\section{References}

1. $\operatorname{CDC}(2013)$ Monitoring selected national HIV prevention and care objectives by using HIV surveillance data-United States and 6 U.S. dependent areas-2011. HIV Surveillance Supplemental Report 18(No. 5)

2. UNAIDS(2012) Report on the global AIDS epidemic.

3. Carbone A, Cesarman E, Spina M, Gloghini A, Schulz TF(2009)HIV-associated lymphomas and gamma-herpesviruses. Blood 113:1213-1224

4. Gopal S, Patel MR, Yanik EL, Stephen R. Cole SR, et al (2013)Temporal trends in presentation and survival for HIV-associated lymphoma in the antiretroviral therapy era. J Natl Cancer Inst 105:1221-1229.
5. Jacobson CA, Abramson JS(2012) HIV-associated Hodgkin's lymphoma: prognosis and therapy in the era of CART.

6. Petrara MR, Freguja R, Gianesin K, Zanchetta M, DeRossi A(2013)EpsteinBarr virus-driven lymphomagenesis in the context of human immunodeficiency virus type1 infection.

7. Kanakry JA, AmbinderRF(2013) EBV-related lymphomas: new approaches to treatment. Curr Treat Options Oncol 14:224-236.

8. Gopal S, Patel MR, Yanik EL, R. Cole SR, Achenbach CJ, et al. (2013)As sociation of early HIV viremia with mortality after HIV associated lymphoma AIDS 27: 2365-2373.

9. Parvaneh N, Filipovich AH, Borkhardt A(2013) Primary immunodeficiencies predisposed to Epstein-Barr virus-driven haematological diseases. Brit $J$ Haematol 162: 573-586.

10. Yanik EL, Napravnik S, Cole SR, Achenbach CJ, Gopal S, et al. (2014) Re lationship of immunologic response to antiretroviral therapy with non-AIDS defining cancer incidence. AIDS 28:979-987.

11. Achenbach CJ, Buchanan AL, Cole SR, Hou L, Mugavero MJ, et al. (2014) HIV viremia and incidence of non-Hodgkin lymphoma in patients successfully treated with antiretroviral therapy. Clin Infect Dis 58:1599-1606

12. d'Amore F, Johansen P,Houmand A, Weisenburger DD, Mortensen LS(1996) Epstein-Barr virus genome in non-Hodgkin's lymphoma occurring in immunocompetent patients: highest prevalence in nonlymphoblastic T-cell lymphoma and correlation with poor prognosis. Blood 87:1045-1055

13. Jarrett RF, Stark GL, White J, Angus B, Alexander FE, et al. (2005) Impact of tumor Epstein-Barr virus status on presenting features and outcome in age-defined subgroups of patients with classic Hodgkin lymphoma: a population-based study. Blood 106:2444-2451

14. Keegan THM, Glaser SL, Clarke CA, Gulley ML, Craig FE, et al. (2005) Epstein-Barr virus as a marker of survival after Hodgkin's lymphoma: a population-based study. J ClinOncol 23:7604-7613.

15. Yoshino T, Nakamura S, Matsuno Y, Ochiai A, Yokoi T, et al. (2006) Epstein-Barr virus involvement is a predictive factor for resistance to chemoradiotherapy of gastric diffuse large B-cell lymphoma. Cancer Sci 97:163-166.

16. Park S, Lee J, Ko YH, Han A, Jun HJ, et al. (2007) The impact of Epstein-Bar virus status on clinical outcome in diffuse large B-cell lymphoma. Blood 110:972-978

17. Asano N, Yamamoto K, Tamaru JI, Oyama T, Ishida F, et al. (2009) Age-related Epstein-Barr virus (EBV)-associated B-cell lymphoproliferative disorders: comparison with EBV-positive classic Hodgkin lymphoma in elderly patients. Blood 113:2629-2636.

18. Chetaille B, Bertucci F, Finetti P, Esterni B, StamatoullasA,et al. (2009) Molecular profiling of classical Hodgkin lymphoma tissues uncovers variations in the tumor microenvironment and correlations with EBV infection and outcome. Blood 113: 2765-2775.

19. Tedeschi R, Bortolin MT, Bidoli E, Zanussi S, Pratesi C, et al. (2012) Assessment of immunovirological features in HIV related non-Hodgkin lymphoma patients and their impact on outcome. J ClinVirol 53:297-301.

20. Khanna R, Burrows SR (2000) Role of cytotoxic T lymphocytes in Epstein-Barr virus-associated diseases. Annu Rev Microbiol 54:19-48.

21. Hislop AD, Taylor GS, Sauce D, Rickinson AB (2007) Cellular responses to viral infection in humans: lessons from Epstein-Barr virus. Annu. Rev. Immunol 25: 587-617.

22. Gonzalez-Farre B, Rovira J, Martinez D, Valera A, Garcia-Herrera A, et al. (2014) In vivo intratumoral Epstein-Barr virus replication is associated with XBP1 activation and early-onset post-transplant lymphoproliferative disorders with prognostic implications. Mod Pathol 1-13.

23. Cochet C, Martel-Renoir D, Greunewald V, Bosq J, Cochet G, et al. (1993) Expression of the Epstein-Barr virus immediate early gene, BZLF1, in nasopharyngeal carcinoma tumor cells. Virology 197:358-365.

24. Martel-Renoir A, Grunewald V, Touitou R, Schwaab G, Joab I(1995) Qualitative analysis of the expression of Epstein-Barr virus lytic genes in nasopharyngeal biopsies. J Gen Virol 76:1401-1408. 
Citation: Maria Eugenia Ariza and Marshall V. Williams (2016) EBV-dUTPase Modulates Host Immune Responses Potentially Altering the Tumor Microenvironment in EBV-associated Malignancies.Curr Res HIV/AIDS (2016): 1-9.

25. Montone KT, Hodinka RL, Salhany KE, Lavi E, Rostami A, et al. (1996) Identification of Epstein-Barr virus lytic activity in post-transplantionlymphoproliferative disease. Mod Pathol 9:621-630.

26. Xue SA, Labrecque LG, Lu QL, Ong SK, Lampert IA, et al. (2002) Promiscuous expression of Epstein-Barr virus in Burkitt's lymphoma from the central Africian country Malawi. Int J Cancer 99:635-643.

27. Kroll J, Li S, Levi M, Weinberg A (2011) Lytic and latent EBV gene expression in transplant recipients with and without post-transplant lymphoproliferative disorder. J ClinVirol 52: 231- 235.

28. Strong MJ, Xu G, Coco J, Baribault C, Vinay DS, et al. (2013) Difference in gastric carcinoma microenvironment stratify according to EBV infection intensity: Implications for possible immune adjuvant therapy.PLoSPathog 9: e1003341.

29. Tsai MH, Raykova A, Klinke O, Bernhardt K, Gartner K, et al. (2013) Spontaneous lytic replication and epitheliotropism define an Epstein-Barr Virus strain found in carcinomas. Cell Reports 5:458-470.

30. Hong GK, Gulley ML, FengWH,Delecluse HJ, Holley-Guthrie E, et al. (2005) Epstein-Barr Virus lytic infection contributes to lymphoproliferative disease in a SCID mouse model. J Virol 79:13993-14003.

31. Jones RJ, Seaman WT, Feng WH, Barlow E, Dickerson S, et al. (2007) Roles of lytic viral infection and IL-6 in early versus late passage lymphoblastoid cell lines and EBV-associated lymphoproliferative disease. Int $\mathrm{J}$ Cance 121:1274-1281.

32. Ma SD, Hedge S, Young KH, Sullivan R, Rajesh D, et al. (2011) A new mode of Epstein-Barr virus infection reveals an important role for early lytic vira protein expression in the development of lymphomas. J Virol 85:165-177.

33. Ma SD, Yu X, Mertz JE, Gumperz JE, Reinheim E, et al. (2012) An Epstein-Barr virus (EBV) mutant with enhanced BZLF1 expression causes lymphomas with abortive lytic EBV infection in a humanized mouse model. $J$ Virol 86:7976-7987.

34. Padgett DA, Hotchkiss AK, Pyter LM, NelsonRJ, YangE, et al. (2004) Epstein-Barr Virus-Encoded dUTPase Modulates Immune Function and Induces Sickness Behavior in Mice. J. Med. Virol. 74:442-448.

35. Glaser R, Litsky ML, Padget DA, Baiocchi RA, Yang EV, et al. (2006) The EBV-encoded dUTPase induces immune dysregulation: Implications for the pathophysiology of EBV-associated disease. Virology 346:205-218.

36. Waldman WJ, Williams MV, Lemeshow SA, Binkley P, Guttridge D, et al (2008) Epstein-Barr virus-encoded dUTPase enhances proinflammatory cytokine production by macrophages in contact with endothelial cells: evidence for depression-induced atherosclerotic risk. Brain Behav Immunity 22:215223.

37. ArizaME, Glaser R, Kaumaya PTP, Jones C,Williams M(2009) The Epstein-Barr Virus (EBV)-encoded dUTPase activates NF-kB through the TLR2 and MyD88-dependent signaling Pathway. J. Immunol 182:851-859.

38. Lerner AM, Ariza ME, Williams M, Jason L, Beqaj S, et al. (2012) Antibody to Epstein-Barr virus deoxyuridine triphosphate nucleotidohydrolase and and Deoxyribonucleotide Polymerase in a Chronic Fatigue Syndrome Subset. PLoS ONE 7:e47891

39. Ariza ME, Rivailler P, Glaser R, Chen M, Williams MV(2013) Epstein-Bar virus encoded dUTPase containing exosomes modulate innate and adaptive immune responses in human dendritic cells and peripheral blood mononuclear cells. PLoS One 8: e69827.

40. Ariza ME, Glaser R, Williams MV (2014) Human herpesviruses encoded dUTPases: A family of proteins that modulate dendritic cells function and innate immunity. Frontiers in Microbiology 504

41. Cheung ST, Huang DP, Hui ABY, Lo KW, Ko CW, et al. (1999) Nasopharyngeal carcinoma cell line (C666-1) consistently harboring Epstein-Barr virus. Int $\mathrm{J}$ Cancer 83:121-126.

42. Ryan JL, Fan H, Glaser SL, Schichman SA, Raab-Traub N, et al. (2004) Epstein-Barr virus quantitation by real-time PCR targeting multiple gene segments: a novel approach to screen for the virus in paraffin-embedded tissue and plasma.JMolDiagn6:378-385.
43. Yang EV, Webster-Marketon Jl, Chen M, Lo KW, Kim SJ, et al.(2010) Glucocorticoids activate Epstein Barr virus lytic replication through the upregulation of immediate early BZLF1 gene expression. Brain Behavlmmun 24:1089 1096.

44. Okano M, Purtilo DT(1995) Simple assay for evaluation of Epstein-Barr virus specific cytotoxic T lymphocytes. J Immunol Methods 184:149-152.

45. de Sanjose S, Bosch R, Schouten T, Verkuijlen S, Nieters A, et al (2007) Epstein-Barr virus infection and risk of lymphoma: immunoblot analysis of antibody responses against EBV-related proteins in a large series of lymphoma subjects and matched controls. Int J Cancer 121:1806-1812.

46. Steven NM, Annels NE, Kumar A, Leese AM, Kurilla MG, et al. (1997) Immediate early and early lytic cycle proteins are frequent targets of the Epstein-Barr virus-induced cytotoxic T cell response. J Exp Med 9:1605-1617.

47. Traylen C, Ramasubramanyan S, Zuo J, Rowe M, Almohammad R, et al. (2015) Identification of Epstein-Barr virus replication proteins in Burkitt's lymphoma cells. Pathogens 4:739-751.

48. Sommer P, Kremmer E, Bier S, Konig S, Zalud P et al. (1996) Cloning and expression of the Epstein-Barr virus-encoded dUTPase: patients with acute, reactivated or chronic virus infection develop antibodies against the enzyme. J Gen Virol 77:2795-2805.

49. Hornung V, Rothenfusser S, Britisch S, Krug A, Jahrsdorfer B, et al. (2002) Quantitative expression of Toll-like receptor 1-10 mRNA in cellular subsets of human peripheral blood mononuclear cells and sensitivity to CpGoligodeoxynucleotides. J Immunol 168:4531-4537.

50. Li J, Qian CH, Zeng YX (2009) Regulatory T cells and EBV associated malignancies. IntImmunopharmacol 9:590-592.

51. Wingate PJ, McAulay KA, Anthony IC, Crawford DH (2009) Regulatory T cell activity in primary and persistent Epstein-Barr virus infection. J. Med. Virol. 81:870-877.

52. Komai-Koma M, Jones L, Ogg GS, Xu D, Liew FY (2004) TLR2 is expressed on activated $\mathrm{T}$ cells as a costimulatory molecule. ProcNatlAcadSci USA 101:3029-3034

53. Liu H, Komai-Koma M, Xu D, Liew FY (2006) Toll-like receptor 2 signaling modulates the functions of CD4+CD25+ regulatory T cells. ProcNatlAcadSci USA 103:7048-7053.

54. Liapis K, Clear A, Owen A, Coutinho R, Greaves P et al (2013) The microenvirnment of AIDS-related diffuse large B-cell lymphoma provides insigh into the pathophysiology and indicates possible therapeutic strategies. Blood $122: 424-433$

55. Kohlhass S, Garden OA, Scudamore C, Turner M, Okkenhaug K, et al. (2009) Cutting Edge: The Foxp3 target mir-155 contributes to the development of regulatory T cells. J Immunol 182:2578-2582.

56. Wang L, Toomey NL, Diaz LA, Walker G, Ramos JC, et al. (2011) Oncogenic IRFs provide a survival advantage for Epstein-Barr virus- or human T-cell leukemia virus type 1-transformed cells through induction of BIC expression. J. Virol. 85:8328-8337.

57. Baumforth KRN, Birgersdotter A, Reynolds GM, Wei W, Kapatai G, et al. (2008) Expression of the Epstein-Barr virus-encoded Epstein-Barr virus nuclear antigen-1 in Hodgkin's lymphoma cells mediates up-regulation of CCL20 and the migration of regulatory T cells. Am J Pathol 173:195-204.

58. Boulland ML, Marquet J, Molinier-Frenkel V, Moller P, Guiter C, et al. (2007) Human IL $4 I 1$ is a secreted L-phenylalanine oxidase expressed by mature dendritic cells that inhibits T-lymphocyte proliferation. Blood 110:220-227.

59. Lasoudris F, Cousin C, Prevost-Blondel A, Martin-Garcia N, Abd-Alsamad I, et al. (2011) IL4I1: an inhibitor of the CD8+ antitumor T-cell response in vivo. Eur. J. Immunol. 41:1629-1638.

60. Hrdinka M, Horejsi V (2014) PAG- a multipurpose transmembrane adaptor protein. Oncogene 33:4881-4892.

61. Jung K, Choi I (2013) Emerging Co-signaling networks in T cell immune regulation. Immune Networks 13:184-193.

62. McKinney EF, Lee JC, Jayne DRW, Lyons PA, Smith KGC (2015) T-cell exhaustion, co-stimulation and clinical outcome in autoimmunity and infection. Nature 523:612-616. 
Citation: Maria Eugenia Ariza and Marshall V. Williams (2016) EBV-dUTPase Modulates Host Immune Responses Potentially Altering the Tumor Microenvironment in EBV-associated Malignancies.Curr Res HIV/AIDS (2016): 1-9.

63. Wherry EJ, Kurachi M (2015) Molecular and cellular insights into T cell exhaustion. Nature Rev Immunol 15:486-499.

64. Ramos de Silva S, Elgui de Oliveria D (2011) HIV, EBV and KSHV: Viral cooperation in the pathogenesis of human malignancies. Cancer Lett 305:175 185.

65. De Paoli P, Carbone A (2015) Microenvironment abnormalities induced by viral cooperation: Impact on lymphomagenesis. Semin Cancer Biol 34:70-80.

66. Hammarskjold ML, Simurada MC (1992) Epstein-Barr virus latent membrane protein transactivates the human immunodeficiency virus type 1 long terminal repeat through induction of NF-kB activity. J Virol 66:6496-6501.

67. Scala G, Quinto I, Ruocco MR, Mallardo M, Ambrosino C, et al. (1993) Epstein-Barr virus nuclear antigen 2 transactivates the long terminal repeat of human immunodeficiency virus type 1. J Virol 67:2853-2861.

68. Lin JC (1993) The Epstein-Barr virus DNA polymerase transactivates the human immunodeficiency virus type 15 " long terminal repeat. BiochemBiophys Res Commun 195:242-249.

69. Colombrina E, Rossi E, Ballon G, Terrin L, Indraccolo S et al. (2004) Human immunodeficiency virus type 1 tat protein modulates cell cycle and apoptosis in Epstein-Barr virus-immortalized B cells. Exp Cell Res 295:539-548.

70. Iyengar S, Schwartz DH (2011) Potentiation of EBV-induced B cell transformation by CXCR4-tropic, but not CCR5-tropic HIV gp120:Implications for HIV-associated lymphomagenesis. AIDS Res Human Retroviruses 27:519523

71. Nazil A, Kafka JK, Ferreira VH, Anipindi V, Mueller K et al. (2013) HIV-1 gp120 induces TLR2-and TLR4-mediated innate immune activation in human female genital epithelium. J Immunol 191:4246-4258.

72. Equils O, Schito ML, Karahashi H, Madak Z, Yarali A, et al. (2003) Toll-like receptor 2 (TLR2) and TLR9 signaling results in HIV-long terminal repeat trans-activation and HIV replication in HIV-1 transgenic mouse spleen cells: Implications of simultaneous activation of TLRs on HIV replication. J Immunol 170:5159-5164
73. Abergel C, Robertson DL, Claverle JM (1999) "Hidden" dUTPase sequence in human immunodeficiency virus type $1 \mathrm{gp} 120$. J Virol 73:751-753.

74. Righetti E, Ballon G, Ometto L, Cattelan AM, Menina C, et al. (2002) Dynamics of Epstein-Barr virus in HIV-1-infected subjects on highly active antiretroviral therapy. AIDS 6:63-73.

75. Calattini S, Sereti I, Scheinberg P, Kimura H, Childs RW,et al. (2010) Detec tion of EBV genomes in plasmablasts/plasma cells and non-B cells in the blood of most patients with EBV lymphoproliferative disorders by using Immuno-FISH. Blood 116:4546-4559.

76. Moir S, Buckner CM, Ho J, Wang W, Chen J, et al. (2010) B cells in early and chronic HIV infection: evidence for preservation of immune function associated with early initiation of antiretroviral therapy. Blood 116: 5571-5579.

77. Mailankody S, Landgren O(2013) HIV, EBV, and monoclonal gammopathy Blood 122: 2924-2925.

78. Ouedraogo DE, Makinson A, Vendrell JP, Casanova ML, Nagot N, et a (2013) Pivotal role of HIV and EBV replication in the long-term persistence of monoclonal gammopathy in patients on antiretroviral therapy Blood 122 3030-3033.

79. Buckner CM, Moir S, Ho J, Wang W, Posada JG et al. (2013) Characterization of plasmablasts in the blood of HIV-infectedviremic individuals: Evidence for nonspecific immune activation. J Virol 87:5800-5811.

80. Laichalk LL, Thorley-Lawson DA(2005) Terminal differentiation into plasma cells initiates the replicative cycle of Epstein-Barr virus in vivo. J Viro 79:1296-1307.

81. Al Tabaa Y, Tuaillon E, Bollore K, Foulongne V, Petitjean G, et al. (2009) Functional Epstein-Barr virus reservoir in plasma cells derived from infected peripheral blood memory B cells. Blood 113:604-611.

82. Al Tabaa Y, Tuaillon E, Jeziorski E, Ouedraogo DE, Bolloré K, et al. (2011) B-cell polyclonal activation and Epstein-Barr viral abortive lytic cycle are two key features in acute infectious mononucleosis. J ClinVirol. 52:33-37. 